\title{
The Effect of Physical Activity and Depressive Mood on Menopausal Symptoms in Postmenopausal Women
}

\author{
Selin Ylmaz ${ }^{1}$, Ismail Arslan ${ }^{1}$, and Duygu Yengil Taci ${ }^{1}$ \\ ${ }^{1}$ Ankara Training and Research Hospital
}

November 4, 2020

\begin{abstract}
Aims: The symptoms of menopause in postmenopausal women adversely affect the quality of life. Menopausal symptoms are more severe with comorbid disorders such as depression; it may be lighter in physically active people. The present study aimed to evaluate the relationship between menopausal symptoms and physical activity and depressive mood. Material and Method: 190 women under 65 years of age who were at least one year passed since their last menstrual period participated in the study. Sociodemographic data form, Menopause Symptom Rating Scale, International Physical Activity Questionnaire Short Form and Beck's Depression Inventory were applied to the participants. Results: It was seen that $51.6 \%$ (98 subjects) of the women who participated in the study had severe menopausal symptoms. $52.6 \%$ (100 subjects) of the participants were physically inactive, and their menopausal symptoms increased as the physical activity scale score decreased ( $\mathrm{p}=0.001$ ). Menopausal symptoms increased as the Beck's Depression Inventory score increased $(\mathrm{p}<0.001)$. It was observed that depression inventory scores decreased as the level of physical activity increased $(\mathrm{p}<0.001)$. Conclusion: Adoption of regular physical activity habits by postmenopausal women and providing treatment to those with depression will contribute to alleviating the severity of menopausal symptoms.
\end{abstract}

\section{Hosted file}

main page.pdf available at https://authorea.com/users/373084/articles/490867-the-effect-ofphysical-activity-and-depressive-mood-on-menopausal-symptoms-in-postmenopausal-women

\section{Hosted file}

Tables.pdf available at https://authorea.com/users/373084/articles/490867-the-effect-ofphysical-activity-and-depressive-mood-on-menopausal-symptoms-in-postmenopausal-women 